\title{
Correction to "Orally Active Opioid $\mu / d$ Dual Agonist MGM-16, a Derivative of the Indole Alkaloid Mitragynine, Exhibits Potent Antiallodynic Effect on Neuropathic Pain in Mice"
}

\author{
In the above article [Matsumoto K, Narita M, Muramatsu N, Nakayama T, Misawa K, \\ Kitajima M, Tashima K, Devi LA, Suzuki T, Takayama H, and Horie S (2014) J Pharmacol \\ Exp Ther 348(3):383-392; DOI:10.1124/jpet.113.208108], the following funding information \\ was omitted: \\ This work was funded by the National Institutes of Health [Grants DA 008863 and NS \\ 026880].
}

The authors regret this error and any inconvenience it may have caused. 